Volume 10, No.4, July - August 2021

International Journal of Advanced Trends in Computer Science and Engineering

Available Online at http://www.warse.org/IJATCSE/static/pdf/file/ijatcse251042021.pdf

https://doi.org/10.30534/ijatcse/2021/251042021

\title{
Review on Controlling and Monitoring of Irrigation System in IOT based smart Agriculture
}

\author{
Sudhanshubala Parida \\ Computer science \& Engineering, Mandsaur University, Mandsaur,458001, India
}

\begin{abstract}
Internet of things is a unique worldwide network that can sense and interact with the environment by means of the internet for the communication and interaction between user and other system. Agriculture plays an important role in the growth of a country like India. As population increases day by day, there is a demand of more food. To get good production in fields, irrigation is necessary for healthy crop. Irrigation is also necessary for the soaking up of nutrients by plants from the soil and improves food security. In our country, India many farmers still use the traditional methods of farming. In India most of the irrigation systems are manually operated by farmers. Farmer suffers from irrigation problem due to improper water utilization, erosion and cutting of cannels. These outdated techniques can be replaced with automated techniques using IOT. In IOT based smart agriculture a system is built for controlling and monitoring the crop fields with the help of sensors and automating the irrigation system. Smart agriculture includes smart irrigation based on accurate real time field data like moisture in soil, environment temperature and water level. This system is used to avoid the direct human intervention while implementing the low cost sensors and Internet of things (IOT).
\end{abstract}

\section{INTRODUCTION}

In India about $60-70 \%$ of population depends upon farming and one third of the nation's capital comes from agriculture. But now people flew from rural to urban there is obstruction in agriculture. To overcome this problem we prefer smart agriculture techniques using Internet Of Things (IOT). Smart agriculture uses modern technology to increase the quality and quantity of agricultural product. IOT enables the objects to be sensed and controlled remotely. Smart agriculture uses modern technology to increase the quality and quantity of agricultural product. Recently skilled migrants all over India and also from outside India had returned to their natives during Pandemic Covid-19 had chosen farming as their profession. These skilled migrants adopt smart agriculture as it take lesser time than traditional farming. IOT in controlling and monitoring system helps to know about water level, moisture in soil, temperature etc....IOT based irrigation system help to the farmer that supply water to crop at right time and amount. This paper shows controlling and monitoring of irrigation system by measuring soil moisture. Soil moisture can be measured by deploying soil moisture sensor with Arduino Uno. The moisture measuring System measures the moisture level and periodically stores the result. The contents of the memory are accessed when ever required. The sensed values are validated and sent to the WI-FI module and from WI-FI module the validated data are sent to the farmer's mobile. The farmers are also notified by SMS. When moister level is low, it would be altered by the system.

Key words: Arduino , ESP8266, Humidity \& Temperature Sensor, Internet of Things, Smart Irrigation, Soil moisture sensor, Water pump.

\section{LITERATURE REVIEW}

This paper focuses on monitoring agriculture by accessing of temperature, soil moisture and relative humidity information by using DHT11 and transfers data to cloud server for remote access [1] .

This paper aims to collect fields data from relative sensors and that data/information sends to the server using Li-Fi technology and Raspberry pi [2].

This paper built a system that monitor crop-field using sensors (Temperature, Humidity and Soil moisture) and to automate the irrigation system. The data from sensors are sent to the Thing speak cloud[3].

This paper includes sensors such as temperature, humidity, soil moisture and rain detector for collecting the field data with Arduino uno, ESP8266 (Wi-Fi module)[4].

This paper includes in the construction of smart grid which is based on Internet of things and the design and implementation in some application links including wind power prediction, condition monitoring of overhead transmission lines, power monitoring, smart home and asset management are elaborated emphatically[5].

This paper includes the water flow controller, $\mathrm{pH}$ sensor, water level monitoring sensor in the pond and temperature and soil moisture sensors are used to get information through External Wi-Fi. Finally data has been sent as a notification through mobile . Based on the acquired value the proposed system calculates $\mathrm{pH}$ level, water level, temperature and Soil Moisture required for irrigation[6]. 
This paper highlighting features of wireless network sensors to connect multiple sensors data and display big-data through Thing speak channel software to perform tasks like weeding, spraying, moisture sensing, bird and animal scaring, keeping vigilance, temperature maintenance, humidity maintenance and weather reports. This development includes smart irrigation with smart control and smart decision based on accurate real time field data[7].

This paper highlights a system for measuring and monitoring soil moisture by linking low-cost soil moisture sensor with Node MCU. It also designed a cloud based platform, so that any users can be able to inspect soil moisture for their specific piece of land through their Smartphone[8].

This paper highlights the smart irrigation system that implements microcomputer, internet driver, water pipes and $\mathrm{C}++$ programming language used with Virtuino for the design of the user interface [9].

This paper uses telegram app for communicating with the cultivators about various environmental factors continuously. This project is also consisting of solar power generation and rainwater harvesting as technology method is implemented along with crop safety [10].

This paper[11] highlights a technology in which a system can monitor the humidity, moisture level and can even detect motions. According to the data received from all the sensors the water pump, cutter and sprayer get automatically activated or deactivated. The methodology not only focuses on the farm but also takes care of the warehouse where all cultivated crops are being stored. The warehouse is embedded with various sensors which help also detect humidity and theft. Based on the humidity sensor reading heater or cooling fan is automatically turned on. Similarly if the motion sensor detects any theft then an alarm is turned on to notify the farmer.

The system in [12] proposed agriculture management system for receiving data about agricultural environment by using sensor network. The system collected sensors data about climate and soil. This system only monitor environment and soil parameters but did not observe irrigation process.

\section{PROPOSED SYSTEM}

In order to increase quality of crops, we must use technologies that analyze soil moisture, temperature and humidity content. The data is collected wirelessly through various sensors. Due to weather condition water level increases or decreases which is not good for crops. This system can be used in both small agricultural land and large farm also. The proposed system has been designed to watering the fields whenever necessary and also control unnecessary water flow into the field or crops.

\section{Algorithm}

Steps that system undergoes

Step-1 First code will be uploaded in Arduino board.

Step-2 The soil moisture sensors and DHT11 sensor are deployed in respective places which continuously send the activities or data to Arduino board.

Step-3 Submerge the motor in water container and motor outlet will be connected with it. Then power will be supplied to it. It also connected with Relay board. One should ensure that the water level should be higher than the motor.

Step-4 The soil moisture sensor detects the moisture content in the soil. DHT11 sensor senses the environment and calculates relative humidity.

Step-5 Water pump will receive the analyzed data from Arduino. When moisture of soil or humidity of environment reaches to its peak and all the requirements and data analyzed by Arduino are satisfied then buzzer will be turned on and Arduino micro controller switch on the water pump automatically.

Step-6 After watering en soil moisture sensor crossed the threshold value; motor will be turned off automatically.

\section{BLOCK DIAGRAM}

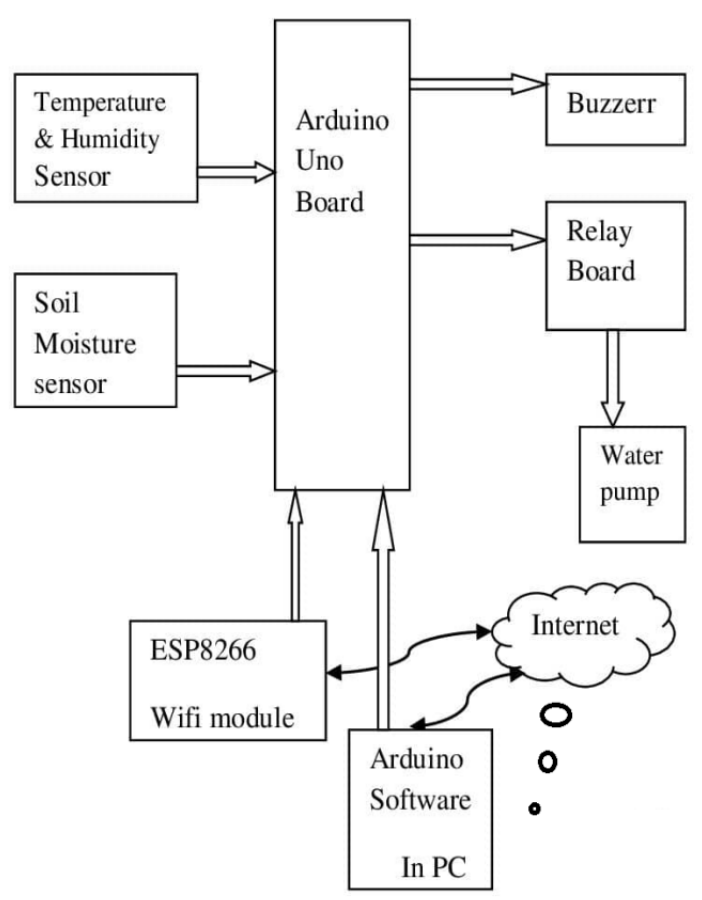




\section{HARDWARE DESCRIPTION}

\section{A. Temperature Identifier:}

This is a water-resistant temperature sensor .This sensor can dictate the temperature and humidity of environment discharge digital signal to data pin. As it is very small, it's not very effective in very large field. It can be used for small farm or for small area.

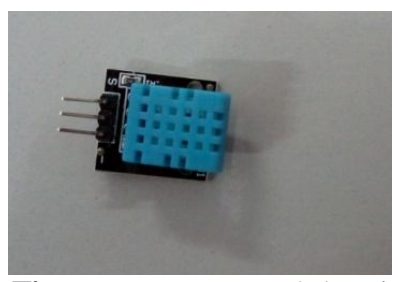

Fig -I temperature \& humidity sensor

\section{B. Soil Moisture Measurement :}

Water content of the soil can be measured by the soil moisture sensor. Capacitance is used by soil moisture sensor to measure the dielectric conductivity of the surrounding. If the soil is wet or moisture content is high motor will be turned OFF or it will not start for watering otherwise the motor will turn ON automatically.

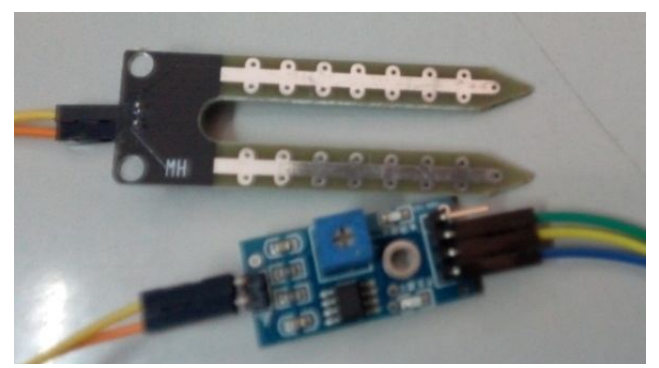

Fig-II Soil Moisture sensor

\section{Arduino Board:}

Arduino Uno is a open source electronics component. Arduino contains microcontroller which is a physical programmable circuit board and IDE (Integrated Development Environment) that runs on a computer used to upload computer code to the Arduino board. We can send a set of instruction to the microcontroller on the Arduino board. Programming in $\mathrm{C}$ widely used for Arduino board. The main advantage is Programmer can write low number of codes.

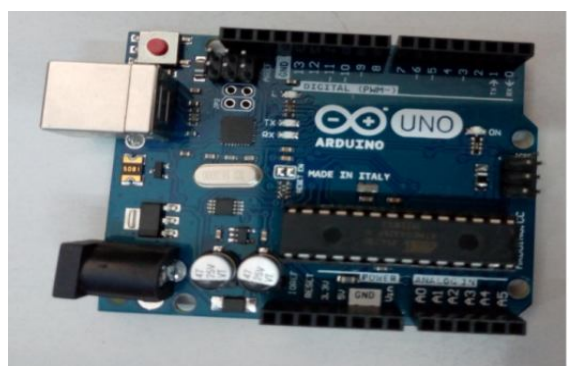

Fig-III Arduino Uno

\section{Water Pump:}

Micro dc 3v-6v submersible pump which can be operated from a $2.5 \sim 6 \mathrm{~V}$ power supply. It can pick up 120 liters per hour with very low current consumption.

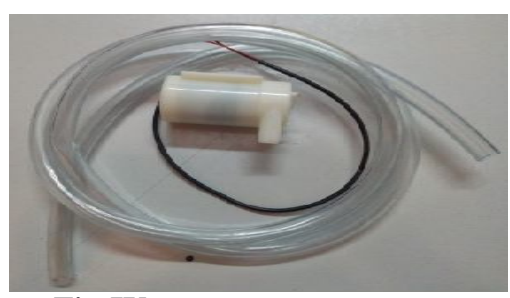

Fig-IV Water pump

\section{E. Relay Board:}

This is also known as Relay module. The blue square component in the middle is known as Relay. The number of relays on the module indicates how many channels of a particular module support. The relay module is used to control the application by turn it $\mathrm{ON}$ or OFF.

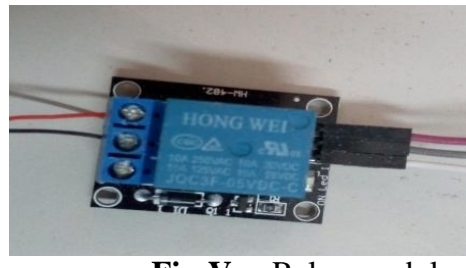

F. Buzzer:

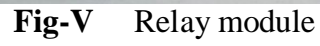

A buzzer is used to give audio warning signal that motor is turn ON/OFF. It works on physio electric concept of creating a sound. It is used for very secure application.

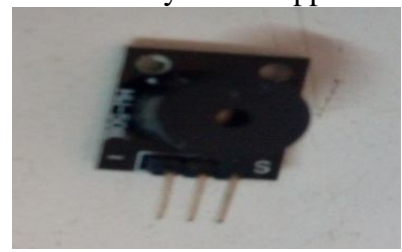

Fig-VI Buzzer 


\section{G. ESP8266:}

ESP8266 module is standalone wireless transceiver which can be used for IoT developments. It enables internet connectivity to embedded IOT applications. Arduino microcontroller needs to set off AT commands to communicate with the ESP8266 module. ESP8266 has a set of GPIO pins (General Purpose Input Output pins) that can be used to "control" external sensors.

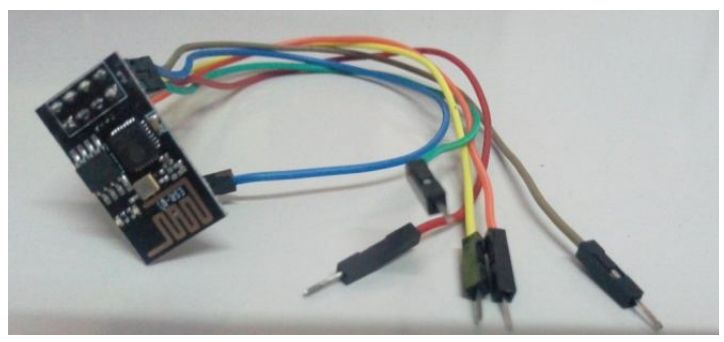

Fig-VII ESP8266

\section{Connections Of Sensors with Arduino Board}

\begin{tabular}{|c|c|c|}
\hline Esp8266 | Arduino & Buzzer & Relay \\
\hline RX $\mid \mathrm{RX}$ & Datapin 12 & Signal $\mid 13$ \\
\hline \begin{tabular}{l|l} 
TX & TX
\end{tabular} & & VCC $15 \mathrm{~V}$ \\
\hline GND | GND & & GND |GND \\
\hline RST | GND & & \\
\hline $3 \mathrm{~V} 3$ | $3 \mathrm{~V}$ & & \\
\hline $\mathrm{EN} \mid 3 \mathrm{~V}$ & & \\
\hline GPIO $0 \mid$ None & & \\
\hline GPIO 2 | None & & \\
\hline Humidity Sensor & Soil Moisture & \\
\hline signal 2 & $\mathrm{G} \mid 8$ & \\
\hline VCC $\mid 5 \mathrm{~V}$ & $\mathrm{Y} \mid \mathrm{GND}$ & \\
\hline -VE |GND & B $3.3 \mathrm{~V}$ & \\
\hline
\end{tabular}

\section{EXPERIMENTAL RESULT}

In this paper a Smart Irrigation system is implemented using Arduino Uno to obtain high crops productivity which reduces human efforts. Many sensors combined with microcontroller of Arduino Board to collect the information. Actual values detected by the system are observed by the farmer and with his intervention irrigation ran automatically at his crop field. Board to collect the information. Actual values detected by the system are observed by the farmer and with his intervention irrigation ran automatically at his crop field.

\section{Before Watering}

Table-I Soil Moisture, humidity\& Temperature

\begin{tabular}{|c|l|l|l|}
\hline \multicolumn{1}{|c|}{ reading } & $\begin{array}{l}\text { Soil } \\
\text { Moisture } \\
\text { value }\end{array}$ & $\begin{array}{l}\text { Humidity } \\
\text { value }\end{array}$ & $\begin{array}{l}\text { Temperature } \\
\text { value } \\
\left({ }^{\circ} \mathrm{C}\right)\end{array}$ \\
\hline $16 / 6 / 2021$ & 123 & 53.00 & 33.80 \\
\hline $17 / 6 / 2021$ & 141 & 66.00 & 31.30 \\
\hline $18 / 6 / 2021$ & 151 & 73.00 & 28.90 \\
\hline $19 / 6 / 2021$ & 170 & 61.00 & 32.00 \\
\hline
\end{tabular}

After watering:-

Table-II Soil Moisture, humidity\& Temperature reading

\begin{tabular}{|l|l|l|l|}
\hline Date & $\begin{array}{l}\text { Soil } \\
\text { Moisture } \\
\text { value }\end{array}$ & $\begin{array}{l}\text { Humidity } \\
\text { value }\end{array}$ & $\begin{array}{l}\text { Temperature } \\
\text { value } \\
\left({ }^{\circ} \mathrm{C}\right)\end{array}$ \\
\hline $19 / 6 / 2021$ & 107 & 61.00 & 32.00 \\
\hline $20 / 6 / 2021$ & 140 & 54.00 & 33.10 \\
\hline $21 / 6 / 2021$ & 154 & 50.00 & 29.80 \\
\hline
\end{tabular}

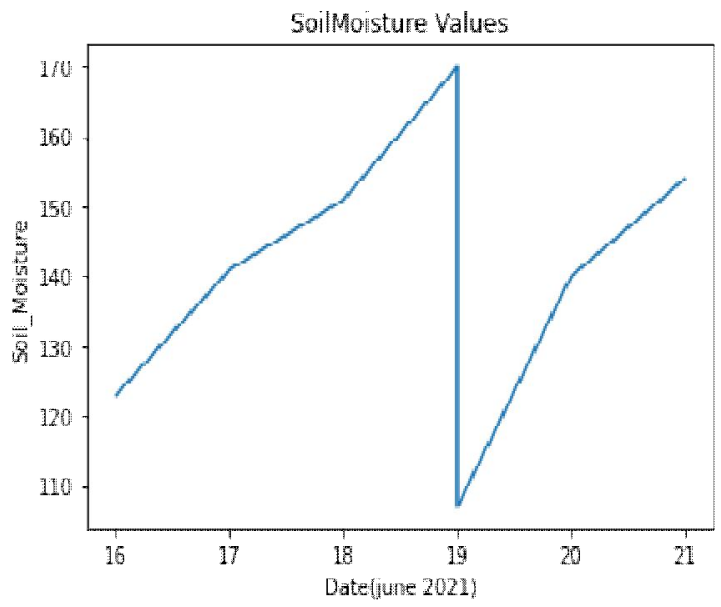

Fig-VIII Soil_Moisture data 


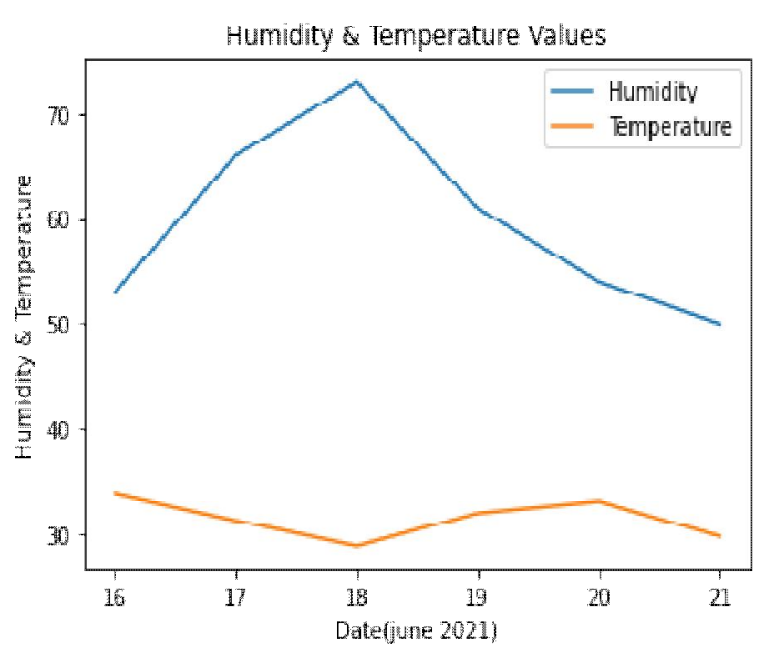

Fig-IX Humidity \& Temperature data

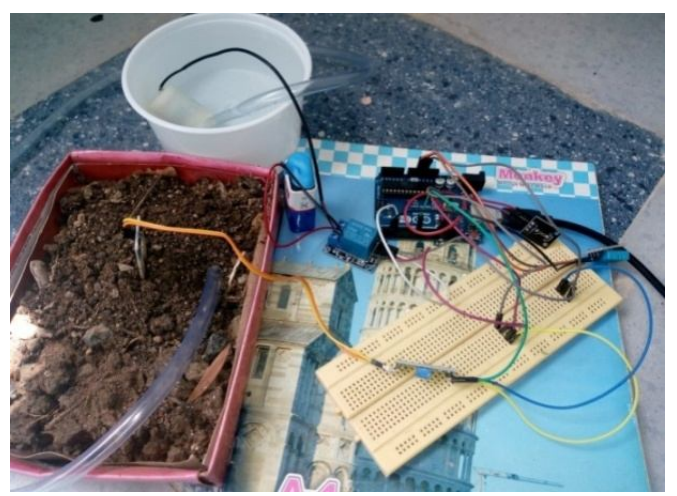

Fig-X Design prototype

\section{CONCLUSION AND FUTURE WORK}

This project is helpful for those farmers who do not have enough time for watering in time. The proposal of using IOT in agriculture is to perform in a smart and more efficient way. The collected data can be helpful when crops are planted in future. This system can improve the way of irrigation system in different region of our country. Sensors of different types are used to collect the information of environmental changes and this information is transmitted through network to the particular devices that initiates the corresponding actions. In future I would develop an android application through which the user can see the sensor data's and that application will also detect animal or human (thief) and turn siren ON and camera will capture it's video and send to user. So that user can aware about his farm's present condition at anytime from anywhere.

\section{REFERENCES}

1. Sharmila Nath, Jayanta kumar Nath, Prof. Kanak Chandra Sarma "IoT Based System for Continuous Measurement and Monitoring of Temperature, Soil
Moisture and Relative Humidity", International Journal of Electrical Engineering \& Technology (IJEET)

Volume 9, Issue 3, May-June 2018.

2. Sangeetha A ,Sarah prisella ,Poovarasi and Mrs.kavitha subramani, “ IOT Based Hybrid System for Precision Agriculture Monitoring Using WSN into modern information and Communication Technology",IJARIIE-ISSN(O)-2395-4396, Vol-4 Issue-2 2018.

3. Erastus Ogunti, PDepartment of Computer Engineering, Federal University of Technology, Akure, Nigeria, "IoT Based Crop Field Monitoring and Irrigation Automation System", International Journal of Innovative Science, Engineering \& Technology, Vol. 6 Issue 3, March 2019.

4. Dr. Sanjay N. Patil , Madhuri B. Jadhav,"Smart Agriculture Monitoring System Using IOT",

International Journal of Advanced Research in Computer and Communication Engineering Vol. 8, Issue 4, April 2019.

5. Liu Hua , Zhang Junguo , Lin Fantao , "Internet of Things Technology and its Applications in Smart Grid”, ELKOMNIKA Indonesian Journal of Electrical Engineering, Vol.12, Issue 2, February 2014.

6. Tigist Hilemariam Senbetu, Kishore Kumar K, G.M. Karpura Dheepan, "IoT Based Irrigation Remote RealTime Monitoring And Controlling Systems", International Journal of Innovative Technology and Exploring Engineering (IJITEE), Volume-8 Issue-7, May, 2019.

7. Kavyasree.V.K, Mala.V, Bhanupriya.R, Vidhya.S, "IOT BASED INTELLIGENT AGRICULTURE MONITORING AND CONTROLLING SYSTEM", International Journal of Advanced Science and Engineering Research(ijaser), Volume- 3, Issue: 1, 2018.

8. Prof. Manjunath R , Chandana M S , Indu , Nayana, Soundarya, "Cloud Based Soil Moisture Measuring System Using IOT in Indian Agriculture", International Journal of Scientific Research and Review, Volume 07, Issue 05, May 2019.

9. Olatunji K.,Oguntimilehin ,Adeyemo, "A Mobile Phone Controllable Smart Irrigation System", International Journal of Advanced Trends in Computer Science and Engineering,Volume 9, Issue 01, January - February 2020.

10. Anjana, Charan Kumar, Monisha , Sahana, "IOT in Agricultural Crop Protection and Power Generation",International Journal of Engineering Research \& Technology, Vol. 9, Issue 05, May-2020.

11. Sweksha Goyal, Unnathi Mundra, Prof. Sahana Shetty, "SMART AGRICULTURE USING IOT", International Journal of Computer Science and Mobile Computing, Vol.8 Issue.5, May- 2019.

12. C. Chavan and P. Karande, "Wireless Monitoring of Soil Moisture, Temperature \& Humidity Using Zigbee in Agriculture", International Journal of Engineering Trends and Technology (IJETT), Vol 11, Issue No. 10, 2014.

13. Adithya Vadapalli, Swapna Peravali \& Venkata Rao Dadi , " Smart Agriculture System using IoT Technology”, International Journal of Advance 
Research in science \& Engineering, Vol 9, Issue No 9, sepetember 2020.

14. G. Vennila, Dr. D. Arivazhagan, Dr.Jayavadivel, "An Investigation Of IOT Based Smart Agriculture", International Journal of Scientific \& Technology

15. Dr.N.Suma, Sandra Rhea Samson, S.Saranya, G.Shanmugapriya and R.Subhashri, "IOT Based Smart Agriculture Monitoring System," International Journal on Recent and Innovation Trends in Computing and Communication, Volume: 5, Issue: 2, pp.177-181, February 2017.

16. Vinita Tyagi, Raman kumar , Gopal Fartyal , Research ,Volume 9, Issue 1, January 2020.
Anant Garg, Dr. Janakkumar . B. Patel , Manjeet kaur ,"IOT Based Agriculture System," International journal on IJESC, Volume 7, Issue 5,2017.

17. Ahmed Imteaj, Tanveer Rahman, Muhammad Kamrul Hossain and Saika Zaman, "IoT based Autonomous Percipient Irrigation System using Raspberry Pi," International Conference on Computer and Information Technology,2016.

18. Ashik Paily, Akshay V Anil, Nimmy Manuel, "IoT BASED FARM AUTOMATION AND CLOUD INTEGRATION", International Journal of Networks and Systems, Volume 8, No.3, April-May 